\title{
NURSING ORGANIZATION AND ADMINISTRATION FOR TUBERCULOUS PATIENTS IN COUNTRY DISTRICTS.
}

\author{
By A. W. FORTESCUE SAYRES, \\ M.D. (BRUX.), M.R.C.S., L.R.C.P., D.P.H. (LONDON), \\ Tuberculosis Officer, Devon County.
}

THE supervision by nurses of tuberculous patients in rural districts is a complicated matter, and one extremely difficult to organize successfully. Nevertheless, it is an important factor in the crusade for the arrest and prevention of tuberculosis, as only by the constant visiting and inspection of these patients (who for the most part belong to the illiterate, careless, and irresponsible class), can we hope that their infective sputum will be regularly dealt with according to instructions, and that the patients themselves will obey and carry out hygienic rules.

\section{The Organization of Nursing for Tuberculous Subjects.}

Some counties appear to be working a nursing system with wholetime nurses, but it is difficult to understand how more than a primary visit can be managed with such large distances to be covered. A weekly visit, or even a monthly visit, would entail so large a staff that the expense would be nearly prohibitive, and visiting out-of-the-way country cottages would present many difficulties. The object of a satisfactory nursing system is to provide the frequent visit of a nurse (at least once weekly) to supervise the efficient disinfection and disposal of sputum, to see that the patient is carrying out regulations and instructions relative to living an hygienic life, and, if a shelter has been granted, that it is being used properly. This frequent visiting can be provided by making use of the County Nursing Associations. In most counties nearly all rural areas are now served by district nurses, three or four villages combining to support a nurse. This is the case in Devon.

Dr. Adkins, the Devon County Medical Officer, has made an arrangement with the County Nursing Association and other unaffiliated associations by which, on application of the Tuberculosis Officer, a nurse visits a tuberculous case once weekly at is. per visit, and administers the nourishment benefit, if such has been granted. The Insurance Committee will, on representation of the Tuberculosis Officer, allow special nursing at the rate of $6 \mathrm{~d}$. per visit for insured patients, the fees not to exceed 5s. per week. The weekly visit is the essential point. Daily visits are not often necessary, only to those bedridden patients 


\section{I58 THE BRITISH JOURNAL OF TUBERCULOSIS}

who have arrived at the last stage of the disease. The expense, therefore, is not great. The grants in aid of nursing, recently promised by the Chancellor of the Exchequer in his Budget, may probably in the future assist greatly the provision of nursing in rural districts.

\section{Uniformity of Action by Nurses.}

There is difficulty in obtaining uniformity of action amongst so many differently trained nurses, and of being assured that they will enforce rules according to the wishes of the Tuberculosis Officer. Patients and people generally have become confused, and in consequence indifferent, by the many and various orders they receive. How is this to be obviated? The following are important points: (I) Enlist the cooperation of the County Superintendent (supervising matron) of the County Nursing Association. This lady is continually travelling, inspecting, and supervising the work of the district nurses. She is able to instruct and obtain compliance to rules which have been agreed upon as essential. (2) Obtain the assistance of the training centres for district nurses. The matrons are usually most ready to assist by instructing the students in rules for tuberculous patients. (3) Personally visit and interview the unaffiliated nurses, pointing out rules you wish adhered to.

Over the county area of South-West Devon, for which one Tuberculosis Officer is responsible, there are thirty-four villages served by district.nurses. Of these villages, twenty-five ( 73 per cent.) are served by County Nursing Association nurses, and are, therefore, under the control of the County Superintendent. Of the remaining nine, two have large nursing institutes under a matron acting in co-operation with the Tuberculosis Officer, seven only are worked by unaffiliated associations. It is, therefore, fairly easy to obtain the necessary uniformity, the chief point being to obtain the co-operation of the County Superintendent.

\section{Rules for Tuberculous Patients.}

The supervision of the efficient disinfection and disposal of sputum is one of the most important duties of the nurse. These domiciliary cases, who are generally in a chronic or advanced stage of disease, and who are expectorating billions of tubercle bacilli per diem, up to the present have been the greatest culprits in spreading infection, and are the most necessary to get under control. Until we have more satisfactory control over these patients, we shall continue to have the contact cases which, unfortunately, are so frequent.

It is not necessary to detail all the rules a nurse should see carried out by tuberculous patients; these are well known, but the following seem worthy of more notice than has hitherto been bestowed upon them:

(I) The prohibition of spitting directly into the fire, upon rags or 
paper, or into a spittoon. (2) Spitting only to be allowed into a cup or sputum-flask containing strong disinfectant, and supplied with a lid, when indoors, and into a pocket-flask containing the same solution when out of doors. (3) The disinfectant used to be of a higher coefficient than carbolic. (4) The solution to be of sufficient strength to have a rapid lethal effect upon tubercle bacillus. The solution, when first prepared, should be at least of strength of $\mathrm{I}$ in 50 , in order to insure that it shall not be below I in too if an equal amount of sputum be added. To prepare the solution, a teaspoonful added to half a tumblerful of water roughly gives a strength of $I$ in $5^{\circ}$. In the homes of the illiterate, the nurse at her weekly visit should prepare sufficient solution to last the week. (5) The sputum to be well mixed with the disinfectant solution. (6) The disinfected sputum to be disposed of morning and evening in a place specified in instructions. (7) In country districts the method of disposal to be by burning if the contents are of not too large a quantity. If burning is impracticable, the disinfected sputum should be buried deep in the mould of the garden.

\title{
THE AIMS AND METHODS OF THE TUBERCULOSIS NURSE.
}

\author{
By Miss MARY RUNDLE, \\ Matron of the Royal Hospital for Diseases of the Chest, City Road, London.
}

THE tuberculosis nurse has now become a recognized and necessary officer in the tuberculosis campaign. The duties of the tuberculosis nurse, more than in any other branch of her profession, require her to teach the principles and practices on which depend the prevention of disease. Thus her position is exceptional, for although the actual nursing may be limited, it is most essential she shall possess the knowledge which will enable her to cope with the emergencies which repeatedly occur. This point should be emphasized, as there is a tendency to think, that for some appointments, notably those of the Tuberculosis Dispensary, other than trained nurses should be entrusted with the work. This suggestion should be deprecated. If the sick and diseased are to be helped towards health, who but a trained nurse can be expected to view in the right proportion the condition of ill-health. And as the fundamental law of successful teaching is to proceed from the known to the related unknown, the untrained woman lacking that fundamental knowledge cannot be expected to become a successful teacher, and for the same reason it is necessary that a nurse acquaint 